\title{
How Do Observers Assess Resolve? - CORRIGENDUM
}

Joshua D Kertzer, Jonathan Renshon and Keren Yarhi-Milo

(First published online 15 February 2021)

doi:10.1017/S0007123418000595, Published by Cambridge University Press, date here.

Keywords: resolve; heuristics; reputation; deterrence theory; costly signals; corrigendum

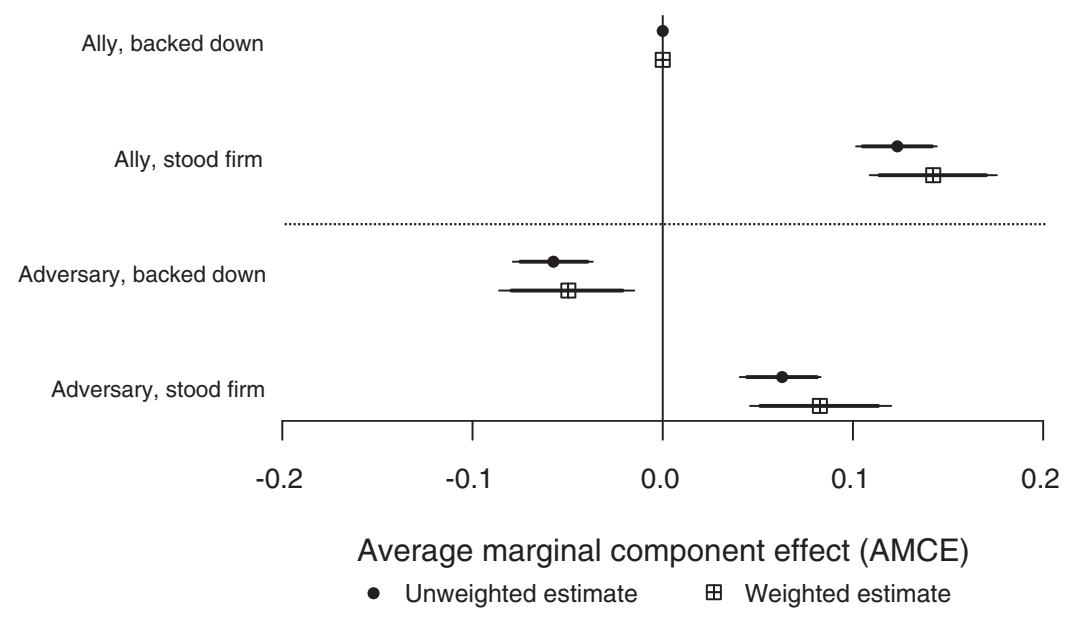

The published version of the article contained a typographical error in panel b of Figure 3, in which the labels in the figure were listed in the wrong order. Please find above the corrected figure panel, which corresponds to the results reported in the main text.

\section{Reference}

Kertzer J, Renshon J and Yarhi-Milo K (2019) How Do Observers Assess Resolve? British Journal of Political Science 51(1), 308-330.

Cite this article: Kertzer JD, Renshon J, Yarhi-Milo K (2021). How Do Observers Assess Resolve? - CORRIGENDUM. British Journal of Political Science 51, 1356. https://doi.org/10.1017/S000712342100003X

(c) Cambridge University Press 2021. 